BMJ Open

Diabetes

Research

\& Care

\title{
Timing of access to secondary healthcare services and lower extremity amputations in patients with diabetes: a case-control study
}

\author{
Claire M Buckley, ${ }^{1,2}$ Fauzi Ali, ${ }^{3}$ Graham A Roberts, ${ }^{3}$ Patricia M Kearney, ${ }^{2}$ \\ Ivan J Perry, ${ }^{2}$ Colin P Bradley ${ }^{1}$
}

To cite: Buckley CM, Ali F, Roberts GA, et al. Timing of access to secondary healthcare services and lower extremity amputations in patients with diabetes: a case-control study. BMJ Open Diabetes Research and Care 2015;3:e000069. doi:10.1136/bmjdrc-2014000069

- Additional material is available. To view please visit the journal (http://dx.doi.org/ 10.1136/bmjdrc-2014000069).

Received 8 November 2014 Revised 11 May 2015 Accepted 18 May 2015

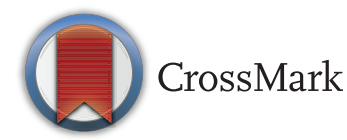

\footnotetext{
${ }^{1}$ Department of General Practice, University College Cork, Cork, Ireland ${ }^{2}$ Department of Epidemiology and Public Health, University College Cork, Cork, Ireland ${ }^{3}$ Department of Endocrinology, University Hospital Waterford, Waterford, Ireland
}

Correspondence to Dr Claire M Buckley; Claire.buckley@ucc.ie

\section{ABSTRACT}

Objective: To investigate the association between timing of patient access to secondary healthcare services for diabetes management and lower extremity amputation (LEA) among patients with diabetes.

Research design and methods: A case-control study was conducted in the secondary healthcare system in Ireland. Cases were 116 patients with diabetes who underwent a first major non-traumatic LEA between 2006 and 2012. Controls were 348 patients with diabetes, over 45 years, admitted to the same hospital as an emergency or electively, frequency-matched for gender, type of diabetes, and year. Data were collected for 7 years prior to the event year. ORs for LEA in patients with diabetes comparing early versus late referral from primary to secondary healthcare were calculated.

Results: Statistically significant risk factors associated with LEA in patients with diabetes included being single, chronic kidney disease, hypertension, and hyperglycemia. Documented retinopathy was a significant protective factor. In unconditional logistic regression analysis adjusted for potential confounders, there was no evidence of a reduced risk of LEA among patients referred earlier to secondary healthcare for diabetes management.

Conclusions: Specialist referral may need to occur earlier than the 7-year cut-off used to demonstrate an effect on reducing LEA risk. Documented retinopathy was associated with reduced risk of LEA, most likely as a proxy for better self-care. Variation in the management of diabetes in primary care may also be impacting on outcomes. Efforts to develop more integrated care between primary and secondary services may be beneficial, rather than focusing on timing of referral to secondary healthcare.

\section{INTRODUCTION}

Lower extremity amputation (LEA) is an important complication of diabetes mellitus. National and global LEA rates vary for reasons such as ethnicity, case definition, and ascertainment of diabetes prevalence. ${ }^{12}$ The effects of clinical and sociodemographic

\section{Key messages}

- Patients with diabetes are at increased risk of lower extremity amputation (LEA). Early referral to secondary healthcare for diabetes management is assumed to prevent the occurrence of LEA.

- Findings from this case-control study do not support an association between earlier patient access to secondary healthcare services for diabetes management and the long-term outcome of LEA.

- Efforts to improve diabetes care should be focused on both primary and secondary healthcare services and promoting integration between the two healthcare settings.

factors on the occurrence of LEA in patients with diabetes are well documented. Long duration of disease, prolonged hyperglycemia, hypertension, dyslipidemia, smoking, neuropathy, peripheral vascular disease (PVD), prior ulcers, and lower socioeconomic status (SES) are recognized risk factors for LEA in patients with diabetes. ${ }^{34}$

It has been suggested that the occurrence of LEA is partially attributable to a failed system of healthcare. ${ }^{5}$ In fact, the International Diabetes Federation (IDF) estimates that up to $85 \%$ of diabetes-related LEAs could be avoided with appropriate and timely preventive and specialist care. ${ }^{6}$ Previous research from the UK suggests that better organized care results in a significant improvement in care for patients with diabetic foot disease and a reduction in major LEA rates. ${ }^{78}$ Debate continues on the most appropriate model of care for the management of diabetes. ${ }^{9} 10$ Traditionally, the Irish model for diabetes care was hospital-based. ${ }^{11}$ All patients with type 1 diabetes and the majority of patients with type 2 diabetes were managed in the secondary healthcare setting, and this has been traditionally 
considered the best available care. However, not all patients with diabetes can be managed in secondary care and there is a need to consider the optimal timing of referral from primary to secondary care. Timing of access to secondary healthcare services and the subsequent occurrence of LEA has not been addressed in previous studies. Thus, the objective of this study was to investigate whether there is an association between the timing of patient access to secondary healthcare for diabetes management and the occurrence of LEA.

\section{METHODS}

\section{Design and exclusion criteria}

Detailed methods have been previously published. ${ }^{12}$ A case-control study design was used to explore service-related, sociodemographic, and clinical variables as predictors of the occurrence of LEA in patients with diabetes. The study was conducted in three regional centers for diabetes care with a dedicated vascular surgery service in the South of Ireland. Cases were consecutive patients with diabetes, over 45 years, who underwent a first major LEA between 2006 and 2012. A major LEA was defined as through or proximal to the ankle joint. ${ }^{13}$ Controls were patients with diabetes, over 45 years, admitted to the same center as an emergency or electively, frequency-matched for gender, type of diabetes, and year. Exclusion criteria for the study were: (1) LEA secondary to trauma or malignancy; (2) age less than 45 years; and (3) residence outside referral area to three regional centers. The same exclusion criteria applied to both cases and controls.

\section{Sample size}

The sample size calculation was based on having adequate power to detect an association between timing of access to secondary healthcare services and LEA in patients with diabetes. For the purposes of this study, we assumed timing of access to secondary healthcare services as a proxy for 'good quality care'. We used the definition of 'good quality care' from the Diabetes Quality of Life Study, a cross-sectional survey of 2049 Irish patients with type 1 and 2 diabetes in $2003 .{ }^{9}$ The prevalence of 'good quality care' in the Diabetes Quality of Life Study was $29 \%$. Assuming a prevalence of the exposure of 'good quality care' in controls of $29 \%$, the target sample size was 107 cases and 321 controls with a view to achieving study power of $90 \%$ at a $5 \%$ significance level to detect a protective effect of early referral to secondary healthcare with an OR of 0.4.

\section{Data collection and measurements}

Data for this study were collected from the three participating centers until the target sample size was achieved. All data were extracted from a combination of discharge data, administrative records, and laboratory results in the secondary healthcare setting during 2012-2013. The event year was the year when the major LEA took place for the cases and the same year for the admission of the controls. Data were collected for 7 years prior to the event year for both cases and controls. The presence of a documented history of the following variables was ascertained from hospital discharge data: PVD, hypertension, dyslipidemia, obesity, ischemic heart disease or cerebrovascular disease, nephropathy, retinopathy, current and/or former smoking exposure, and any previous minor LEAs. An expert panel comprising representatives from endocrinology, general practice, and public health convened to decide which services are involved in diabetes management in the Irish healthcare setting. Services deemed to be involved in diabetes management were endocrinology, ophthalmology, renal medicine, cardiology, vascular surgery, and podiatry. Data on timing of first contact with secondary healthcare for diabetes management from any of the included services were extracted from administrative records and were collected as three categories: no contact or within 1 year prior to event (late referral), within 2-3 years prior to event (intermediate referral), or within 4-7 years prior to event (early referral). Data on marital status and SES were also extracted from administrative records. Marital status was classified into four categories: single, married, widowed, or divorced and analyzed as a binary variable: single or ever married. Within Ireland, residents accessing public healthcare are divided into two categories: (1) those that hold a medical card and qualify for means-tested, state-assisted healthcare insurance and (2) non-card holders, who are entitled to public hospital services at a low cost but who must pay for general practitioner (GP) visits. ${ }^{14}$ Possessing a medical card reflects lower SES. SES was classified depending on the possession of a medical card or not. Glycated hemoglobin (HbAlc) levels when available were extracted from laboratory records from four time points: $1,3,5$, and 7 years prior to event. Where more than one HbAlc result was recorded at a particular time point, the highest value was extracted.

\section{Statistical analysis}

Stata V.12C was used for statistical analysis. Descriptive analysis was performed, comparing the distribution of variables among cases and controls and summarizing using frequencies (percentages) and means (95\% CIs). Comparison of proportions was performed using the $\chi^{2}$ statistic for categorical variables and comparison of means was performed using the two-tailed, unpaired Student $\mathrm{t}$ test for continuous variables. The pattern of missing data for HbAlc levels was described. The association between HbAlc and time was modeled using a mixed-effects linear regression model that allowed variation of the slopes and intercepts between individual participants and variation of the average slopes and intercepts between cases and controls.

Univariate binary logistic regression was used to explore relationships between predictor variables and the outcome of LEA. Multiple logistic regression models 
adjusted for age determined the associations between exploratory variables and LEA with adjustment for potential confounders. Initially, a partially adjusted model included age, timing of first contact with secondary healthcare services involved in the management of diabetes, variables used for frequency matching, and those variables significant in the univariate analyses. Variables known to be on the causal pathway (PVD and history of minor LEA) were excluded. A fully adjusted model then added variables known to be important to the outcome of LEA in patients with diabetes from the literature and clinical practice (SES and smoking). The final model was assessed for collinearity using the variance inflation factor (VIF). Model fit was assessed with Hosmer-Lemeshow's goodness-of-fit test. For all analyses, a $\mathrm{p}$ value of less than 0.05 was considered to indicate statistical significance.

Since cases and controls were frequency-matched, unconditional logistic regression with matching variables as covariates was employed. Conditional logistic regression was also performed to assess for overmatching. ${ }^{15}$

\section{RESULTS}

Table 1 summarizes the main characteristics of both cases and controls. The majority of participants were men $(81 \%$ vs $19 \%$ women). The distribution of gender and type of diabetes are similar, reflecting the frequency matching.

The pattern of missing HbAlc data was similar for cases and controls (table 2). Figure 1 outlines HbA1c levels, separately for cases and controls, over the 7 years included in the study. HbA1c levels were significantly higher in the cases 7,5 , and 3 years prior to the event year and dropped more steeply over time $(\mathrm{p}=0.003)$.

The results of the unconditional and conditional analyses were similar (data not shown). Therefore, only the unmatched analyses are reported here.

In partially and fully adjusted models, timing of patient access to secondary healthcare services for diabetes management did not predict LEA (table 3). A history of retinopathy was a statistically significant protective factor for LEA, while being single, a history of chronic kidney disease and higher HbA1c levels 3 years prior to the event were statistically significant risk factors for LEA in partially and fully adjusted models.

There was no evidence of collinearity between predictor variables included in the final fully adjusted logistic regression model; mean VIF 1.2 (range 1.06-1.43). Hosmer-Lemeshow's goodness-of-fit test indicated that the model fits the data well $(\mathrm{p}=0.2)$.

\section{DISCUSSION}

This study did not detect a protective effect for LEA of early referral to secondary healthcare services for diabetes management. The results suggest that the traditional hospital-based model of care in Ireland was not successful in preventing the development of LEAs in patients with diabetes. However, the results of this study need to be interpreted with caution and a number of limitations, particularly associated with the study design, need to be considered.

A cohort study would be the ideal design for this research question. However, LEAs in patients with diabetes are rare events with long latency periods, so a sufficiently large cohort study powered to detect relevant differences was not feasible. A case-control study design was chosen instead. A challenge with case-control studies is the identification and enrollment of suitable control participants. ${ }^{16}{ }^{17}$ A major potential predictor of diabetes complications is disease duration. ${ }^{18}$ Ideally, controls with similar diabetes duration would be selected. However, owing to the lack of a diabetes register in Ireland, this was not possible. ${ }^{19}$ Instead, frequency matching was used for gender, type of diabetes, year, and hospital of admission. To minimize selection bias, patients with diabetes admitted both electively and as an emergency were included as controls. Left censoring of age was also applied, with all participants over 45 years as most LEAs occur in this age group.

Available computerized sources of secondary healthcare data were used for data collection purposes: coded hospital discharge data, administrative records of appointments with healthcare professionals, and laboratory records. In earlier work, we have shown hospital discharge data in Ireland to be reliable for LEA and diabetes. ${ }^{20}$ However, measures of covariates may have been measured with incomplete precision, so there may be residual confounding in the analysis. ${ }^{21}$ Another issue of concern may be the precision of measurement of timing of access to secondary healthcare services from administrative data. The same methods were used for cases and controls, and thus any measurement error present is likely to be non-differential between cases and controls.

This study did not detect a protective effect of timing of access to hospital-based services on LEA. Worldwide, studies have demonstrated LEA risk reduction with better organized care, including the establishment of multidisciplinary teams (MDTs) and structured care pathways and protocols. ${ }^{7}{ }^{22}$ In 2011, a model of care for the diabetic foot, based on the National Institute for Health and Care Excellence (NICE) guidelines, was introduced in Ireland to guide management of patients with diabetes. ${ }^{23}{ }^{24}$ The important role of the MDT was emphasized and new podiatry posts were approved nationally. This study spans 2006-2012 with retrospective data collection extending back to 1999. Improvements in the organization of diabetes care in hospitals in Ireland are ongoing. It may be that the quality of diabetes care in the secondary healthcare setting did not reach the standard outlined in the guidelines in the early part of the study period, and this is the reason a protective effect was not detected.

Alternatively, perhaps no association was detected due to exclusion of the earlier and more critical time points. 
Table 1 Characteristics of cases and controls

\begin{tabular}{|c|c|c|c|}
\hline Variables & $\begin{array}{l}\text { Cases }(n=116) \\
\text { Means }(95 \% \mathrm{Cl}) \\
n(\%)\end{array}$ & $\begin{array}{l}\text { Controls }(n=348) \\
\text { Means }(95 \% \mathrm{Cl}) \\
\mathrm{n}(\%)\end{array}$ & p Value \\
\hline \multicolumn{4}{|l|}{ Demographics } \\
\hline Age & 70.8 (68.7 to 72.7$)$ & $69.4(68.4$ to 70.5$)$ & 0.20 \\
\hline Male & $94(81)$ & $282(81)$ & \\
\hline Lower SES & $95(82)$ & $272(78)$ & 0.40 \\
\hline Single & $46(40)$ & $69(20)$ & $<0.00$ \\
\hline Type 2 diabetes & $102(87)$ & $301(87)$ & 0.90 \\
\hline \multicolumn{4}{|c|}{ Timing of first contact with any secondary healthcare services that manage diabetes } \\
\hline None or within 1 year prior to event & $43(37)$ & $154(44)$ & 0.20 \\
\hline Within 2-3 years prior to event & $15(13)$ & $51(15)$ & \\
\hline Within $4-7$ years prior to event & $58(50)$ & $143(41)$ & \\
\hline \multicolumn{4}{|l|}{ Cardiovascular risk factors } \\
\hline Smoking* & $55(47)$ & $138(40)$ & 0.10 \\
\hline Hypertension & $75(65)$ & $185(53)$ & 0.03 \\
\hline Obesity & $14(12)$ & $28(8)$ & 0.20 \\
\hline Dyslipidemia & $32(28)$ & $71(20)$ & 0.10 \\
\hline \multicolumn{4}{|l|}{ Comorbidities } \\
\hline CKD & $46(40)$ & $90(26)$ & $<0.00$ \\
\hline Retinopathy & $23(20)$ & $106(30)$ & 0.03 \\
\hline IHD/CVD & $61(53)$ & $171(49)$ & 0.50 \\
\hline PVD & $86(74)$ & $59(17)$ & $<0.00$ \\
\hline Minor LEA & $32(28)$ & $2(0.6)$ & $<0.00$ \\
\hline \multicolumn{4}{|l|}{$\mathrm{HbA1c}$} \\
\hline 1 year prior to event & 7.6 (7.2 to 8.0$)$ & 7.6 (7.4 to 7.7 ) & 0.80 \\
\hline 3 years prior to event & 8.7 (8.2 to 9.3$)$ & $7.9(7.7$ to 8.1$)$ & 0.01 \\
\hline 5 years prior to event & 8.8 (8.2 to 9.4$)$ & 7.9 (7.6 to 8.2$)$ & 0.01 \\
\hline 7 years prior to event & 8.9 (8.2 to 9.8$)$ & 7.9 (7.5 to 8.3$)$ & 0.01 \\
\hline
\end{tabular}

CKD, chronic kidney disease; CVD, cerebrovascular disease; HbA1c, glycated hemoglobin; IHD, ischemic heart disease; LEA, lower extremity amputation; PVD, peripheral vascular disease; SES, socioeconomic status.

For this study, electronic records were only available for a 7-year window, thus limiting the study time period. Referral to secondary healthcare services may need to occur earlier than the 7-year cut-off used in this study to determine whether early referral reduces the risk of LEA in patients with diabetes. First contact with secondary healthcare services within 7 years of the event may be too late in the causal pathway to influence LEA. In a previous nested case-control study determining predictors of LEA in a cohort of patients with diabetes, a positive association was detected between LEA risk and increased number of diabetes education encounters in the period 10 years or more before LEA. ${ }^{25}$ This was attributed to channeling bias. Such a source of bias may also have impacted on our results.

Table 2 Pattern of missing data for glycated hemoglobin at different time points

\begin{tabular}{llll}
\hline $\begin{array}{l}\text { Time point (year(s) prior } \\
\text { to event) }\end{array}$ & $\begin{array}{l}\text { Cases } \\
\mathbf{n}(\%)\end{array}$ & $\begin{array}{l}\text { Controls } \\
\mathbf{n}(\%)\end{array}$ & p Value \\
\hline 1 & $14(12)$ & $36(10)$ & 0.60 \\
3 & $37(32)$ & $92(26)$ & 0.30 \\
5 & $69(59)$ & $207(59)$ & 1.00 \\
7 & $90(78)$ & $285(82)$ & 0.30 \\
\hline
\end{tabular}

As this study is restricted to the secondary healthcare setting, we have an incomplete picture of the services provided. While this may be a major limitation in some countries, it is less of a concern in Ireland where a hospital-based model of care previously prevailed. ${ }^{26}$ Our

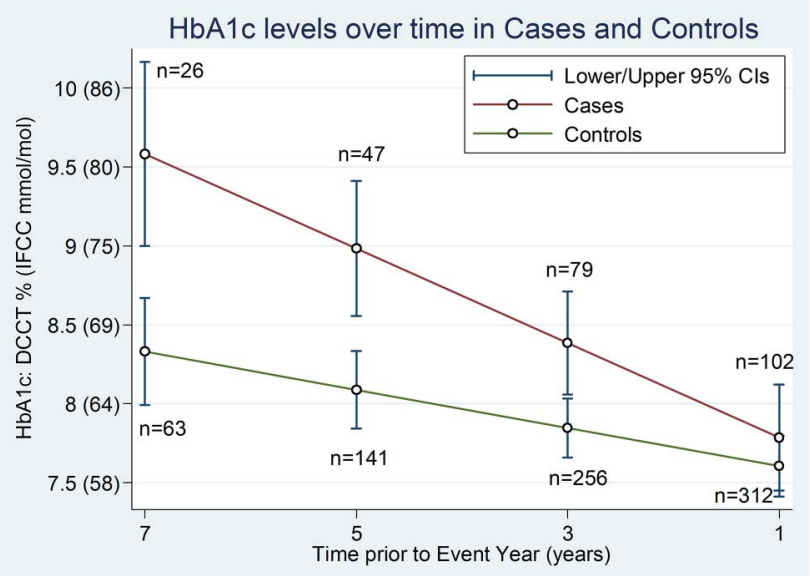

Figure $1 \mathrm{HbA1c}$ levels over time in cases and controls (DCCT, Diabetes Control and Complications Trial; HbA1c, glycated hemoglobin; IFCC, International Federation of Clinical Chemistry). 
Table 3 Partially and fully adjusted ORs and 95\% Cl for predictors of LEA

\begin{tabular}{|c|c|c|c|c|}
\hline Variable & Partially adjusted OR* & p Value & Fully adjusted OR† & p Value \\
\hline \multicolumn{5}{|l|}{ Demographics } \\
\hline Age & $1(0.9$ to 1.1$)$ & 0.1 & $1(0.9$ to 1.1$)$ & 0.20 \\
\hline Male & $1.3(0.6$ to 2.6$)$ & 0.5 & $1.3(0.6$ to 2.6$)$ & 0.50 \\
\hline Lower SES & 3.9 (2.0 to 7.5$)$ & $<0.00$ & $1.7(0.7$ to 4.1$)$ & 0.30 \\
\hline Single & & & $3.7(1.9$ to 7.2$)$ & $<0.00$ \\
\hline \multicolumn{5}{|c|}{ Timing of first contact with any secondary healthcare services that manage diabetes } \\
\hline None or within 1 year prior to event & Reference & & Reference & \\
\hline Within $2-3$ years prior to event & $1.4(0.6$ to 3.5$)$ & 0.5 & $1.3(0.5$ to 3.4$)$ & 0.50 \\
\hline Within $4-7$ years prior to event & 1.7 (0.8 to 3.3$)$ & 0.1 & 1.6 (0.8 to 3.3$)$ & 0.20 \\
\hline \multicolumn{5}{|l|}{ Cardiovascular risk factors } \\
\hline Smoker & 1.7 (0.9 to 3.2$)$ & 0.1 & $1.1(0.6$ to 2.0$)$ & 0.80 \\
\hline Hypertension & & & 1.7 (0.9 to 3.3$)$ & 0.10 \\
\hline \multicolumn{5}{|l|}{ Comorbidities } \\
\hline CKD & $2.6(1.4$ to 4.9$)$ & 0.002 & $2.6(1.4$ to 4.8$)$ & 0.03 \\
\hline Retinopathy & $0.4(0.2$ to 0.8$)$ & 0.01 & $0.4(0.2$ to 0.7$)$ & 0.01 \\
\hline \multicolumn{5}{|l|}{$\mathrm{HbA} 1 \mathrm{c}$} \\
\hline 3 years prior to event ( 1 unit change) & $1.3(1.1$ to 1.5$)$ & 0.001 & $1.3(1.1$ to 1.5$)$ & $<0.00$ \\
\hline
\end{tabular}

findings are generalizable to countries with a predominant hospital-based model of diabetes care.

Previous studies have demonstrated a positive correlation between retinopathy and LEA. ${ }^{18} 2728$ However, in this study, the presence of documented retinopathy was associated with reduced risk of LEA, most likely as a proxy for better self-care. It is biologically implausible that the presence of retinopathy protects against the risk of LEA. Prior to the introduction of a national diabetic retinal screening programme in 2013, the delivery of diabetic retinopathy screening in Ireland was ad hoc. $^{29}{ }^{30}$ Our counterintuitive finding may reflect a selfselection bias whereby patients who chose to seek out retinopathy screening may also actively manage their diabetes in ways that affect their LEA risk. Alternatively, their GPs may be more vigilant about their diabetes management resulting in more referral for retinopathy screening and less risk of LEA, perhaps by more referrals to podiatry services.

A hazardous effect of being single on the risk of LEA was detected. While the protective effects of marriage on morbidity and mortality have been previously documented in Ireland and worldwide,$^{31-33}$ this is the first study to identify an effect of being single on the risk of LEA in patients with diabetes.

High HbA1c levels are a known risk factor for LEA. ${ }^{34}$ While acknowledging high levels of missing data at the earlier time points (table 2), HbA1c levels were significantly higher in cases than controls 7, 5, and 3 years prior to the event year but not 1 year prior to the event. Levels dropped in the cases during the study period, which suggests active management strategies. Recently, the Epidemiology of Diabetes Interventions and Complications (EDIC) study reported a reduced prevalence of diabetes complications among those randomly assigned to intensive glucose control early in the disease process; this is described as the 'metabolic memory' phenomenon. ${ }^{36}$ In our study, even 7 years of diabetes management in secondary healthcare services did not prevent LEA. Intensive therapy should be initiated as early as possible in the attempt to reduce HbA1c levels to target and prevent LEA.

In conclusion, the results of this study suggest that a traditional hospital-based model of care was not successful in preventing the development of LEAs in patients with diabetes. However, the protective effect of retinopathy on LEA risk suggests that other factors influence access to care and subsequent outcomes. The most appropriate delivery of diabetes care is a hugely debated topic. In general, there is growing consensus on the principles of integrated care but opinions differ on how best to implement integrated care in practice. ${ }^{37}$ Currently, the Irish healthcare system is undergoing reform, with a shift toward more integration between primary and secondary healthcare for diabetes management. ${ }^{38}$

Possible reasons this study did not detect a benefit from earlier referral to secondary healthcare services may be that the study period of 7 years was too short or that MDTs and structured care pathways and protocols are only now becoming established in Irish hospitals. Previously, patients with diabetes who were under the care of secondary healthcare services were not achieving adequate control. Or perhaps, more integration with primary care is required. ${ }^{39}$

As the population with diabetes continues to rise, it is anticipated that this could lead to a further increase in the 
number of LEAs in patients with diabetes. ${ }^{40}$ Future research should further explore the finding in this study that earlier referral to secondary care does not protect against LEA risk using more robust study designs. The effectiveness of organizational changes to diabetes care currently being introduced in Ireland on the outcome of LEA in the population with diabetes should also be evaluated.

Acknowledgements The authors would like to thank the staff in the participating centers who kindly facilitated data collection and Dr Anthony Fitzgerald for his help with statistical analysis.

Contributors CMB conceived and designed the study, extracted the data, conducted the outcomes analyses, and wrote the paper. FA extracted the data and approved the final version to be published. GAR designed the study, reviewed the analyses, and revised the paper. PMK designed the study, reviewed the analyses, and revised the paper. IJP designed the study, reviewed the analyses, and revised the paper. CPB designed the study, reviewed the analyses, and revised the paper. All authors read and approved the final version.

Funding This project is funded partially by the Health Research Board, Ireland (grant reference number: HPF/2009/79) and partially by the Irish College of General Practitioners (Research and Education Foundation).

Competing interests None declared.

Ethics approval Ethical approval was granted by the Clinical Research Ethics Committee of the Cork Teaching Hospitals.

Provenance and peer review Not commissioned; externally peer reviewed.

Data sharing statement No additional data are available.

Open Access This is an Open Access article distributed in accordance with the Creative Commons Attribution Non Commercial (CC BY-NC 4.0) license, which permits others to distribute, remix, adapt, build upon this work noncommercially, and license their derivative works on different terms, provided the original work is properly cited and the use is non-commercial. See: http:// creativecommons.org/licenses/by-nc/4.0/

\section{REFERENCES}

1. Moxey P, Gogalniceanu P, Hinchliffe R, et al. Lower extremity amputations - a review of global variability in incidence. Diabet Med 2011;28:1144-53.

2. Kennon B, Leese GP, Cochrane L, et al. Reduced incidence of lower-extremity amputations in people with diabetes in Scotland: a nationwide study. Diabetes Care 2012;35:2588-90.

3. Gamba MA, Gotlieb SLD, Bergamaschi DP, et al. Lower extremity amputations in diabetic patients: a case-control study. Rev Saúde Pública 2004:38:399-404.

4. Venermo M, Manderbacka K, Ikonen T, et al. Amputations and socioeconomic position among persons with diabetes mellitus, a population-based register study. BMJ Open 2013;3:e002395.

5. Sussman KE, Reiber G, Albert SF. The diabetic foot problem-a failed system of health care? Diabetes Res Clin Pract 1992;17:1-8.

6. Position Statement-the Diabetic Foot [article online]. http://www.idf. org/position-statement-diabetic-foot

7. Canavan RJ, Unwin NC, Kelly WF, et al. Diabetes- and nondiabetes-related lower extremity amputation incidence before and after the introduction of better organized diabetes foot care. Diabetes Care 2008;31:459-63.

8. Krishnan S, Nash F, Baker N, et al. Reduction in diabetic amputations over 11 years in a defined U.K. population. Diabetes Care 2008;31:99-101.

9. Collins MM, O'Sullivan T, Harkins V, et al. Quality of life and quality of care in patients with diabetes experiencing different Models of Care. Diabetes Care 2009;32:603-5.

10. Renders CM, Valk GD, Griffin S, et al. Interventions to improve the management of diabetes mellitus in primary care, outpatient and community settings. Cochrane Database Syst Rev 2001;(1): CD001481.
11. Brennan C, Harkins V, Perry IJ. Management of diabetes in primary care: a structured-care approach. Eur J Gen Pract 2008;14:117-22.

12. Buckley CM, Ali F, Roberts G, et al. Timing of access to secondary healthcare services for diabetes management and lower extremity amputation in people with diabetes: a protocol of a case-control study. BMJ Open 2013;3:e003871.

13. Buckley CM, O'Farrell A, Canavan RJ, et al. Trends in the incidence of lower extremity amputations in people with and without diabetes over a five-year period in the Republic of Ireland. PLoS ONE 2012;7: e41492.

14. Goodney PP, Holman K, Henke PK, et al. Regional intensity of vascular care and lower extremity amputation rates. $J$ Vasc Surg 2013;57:1471-80.

15. Spitzer WO, Lewis MA, Heinemann LAJ, et al. Third generation oral contraceptives and risk of venous thromboembolic disorders: an international case-control study. BMJ 1996; 312:83-8.

16. Grimes DA, Schulz KF. Compared to what? Finding controls for case-control studies. Lancet 2005;365:1429-33.

17. Schulz KF, Grimes DA. Case-control studies: research in reverse. Lancet 2002;359:431-4.

18. Hamalainen $\mathrm{H}$, Ronnemaa $\mathrm{T}$, Halonen JP, et al. Factors predicting lower extremity amputations in patients with type 1 or type 2 diabetes mellitus: a population-based 7-year follow-up study. $J$ Intern Med 1999;246:97-103.

19. O'Mullane M, McHugh S, Bradley CP. Informing the development of a national diabetes register in Ireland: a literature review of the impact of patient registration on diabetes care. Inform Prim Care 2011;18:157-68.

20. Buckley CM, Kearney PM, Ali F, et al. Concordance studies between hospital discharge data and medical records for the recording of lower extremity amputation and diabetes in the Republic of Ireland. BMC Res Notes 2013:6:148.

21. Burns EM, Rigby E, Mamidanna R, et al. Systematic review of discharge coding accuracy. $J$ Public Health 2012;34:138-48.

22. Dargis V, Pantelejeva O, Jonushaite A, et al. Benefits of a multidisciplinary approach in the management of recurrent diabetic foot ulceration in Lithuania: a prospective study. Diabetes Care 1999;22:1428-31.

23. Health Service Executive. Model of care for the diabetic foot [article online], 2011. http://www.hse.ie/eng/about/Who/clinical/natclinprog/ diabetesprogramme/modelofcarediabetes.pdf

24. Guidelines on prevention \& management of foot problems in type 2 diabetes [article online], 2004. http://guidance.nice.org.uk/CG10

25. Selby JV, Zhang D. Risk factors for lower extremity amputation in persons with diabetes. Diabetes Care 1995;18:509-16.

26. McDaid D, Wiley M, Maresso A, et al. Ireland: health system review. Health Syst Transition 2009:11:1-268.

27. Chaturvedi N, Stevens LK, Fuller JH, et al. Risk factors, ethnic differences and mortality associated with lower-extremity gangrene and amputation in diabetes. The WHO multinational study of vascular disease in diabetes. Diabetologia 2001; 44:S65-71.

28. Moss SE, Klein R, Klein BE. The 14-year incidence of lower-extremity amputations in a diabetic population. The Wisconsin Epidemiologic Study of Diabetic Retinopathy. Diabetes Care 1999;22:951-9.

29. McHugh S, Buckley C, Murphy K, et al. Quality-assured screening for diabetic retinopathy delivered in primary care in Ireland: an observational study. BJGP 2013;63:e134-40.

30. Mc Hugh S, Marsden P, Brennan C, et al. Counting on commitment; the quality of primary care-led diabetes management in a system with minimal incentives. BMC Health Serv Res 2011;11:348.

31. Corcoran $P$, Nagar A. Suicide and marital status in Northern Ireland. Soc Psychiatry Psychiatr Epidemiol 2010;45:795-800.

32. Molloy GJ, Stamatakis E, Randall G, et al. Marital status, gender and cardiovascular mortality: behavioural, psychological distress and metabolic explanations. Soc Sci Med 2009; 69:223-8.

33. Scafato E, Galluzzo L, Gandin C, et al., for the IWG. Marital and cohabitation status as predictors of mortality: a 10-year follow-up of an Italian elderly cohort. Soc Sci Med 2008;67:1456-64.

34. Adler A, Erqou S, Lima TAS, et al. Association between glycated haemoglobin and the risk of lower extremity amputation in patients with diabetes mellitus-review and meta-analysis. Diabetologia 2010;53:840-9. 
35. Zhao W, Katzmarzyk PT, Horswell R, et al. HbA1c and lower-extremity amputation risk in low-income patients with diabetes. Diabetes Care 2013;36:3591-8.

36. Martin CL, Albers JW, Pop-Busui R. Group ftDER: neuropathy and related findings in the diabetes control and complications trial/ epidemiology of diabetes interventions and complications study. Diabetes Care 2014;37:31-8.

37. Godlee F. Integrated care is what we all want. BMJ 2012;344:e3959.
38. A practical guide to integrated type 2 diabetes care [article online]. 2008. http://www.hse.ie/eng/services/Publications/topics/Diabetes/ A_Practical_Guide_to_Integrated_Type_II_Diabetes_Care.pdf

39. Schaper NC, Apelqvist J, Bakker K. Reducing lower leg amputations in diabetes: a challenge for patients, healthcare providers and the healthcare system. Diabetologia 2012;55:1869-72.

40. Boulton AJ, Vileikyte L, Ragnarson-Tennvall G, et al. The global burden of diabetic foot disease. Lancet 2005;366:1719-24. 